\title{
Exploring Motivations of Volunteer Undergraduate Head Mentors in Engi- neering Outreach to Underserved and Underrepresented K-12 Mentees
}

\section{Jennifer L Sullivan, Rice University}

Jenny works as a research engineer at Rice University, where she splits her time between helping to coordinate the DREAM - Achievement through Mentorship program and conducting research in rehabilitation robotics. She holds a bachelor's degree from Rice University and a master's degree from the University of British Columbia, both in mechanical engineering. She enjoys doing outreach work to increase diversity in STEM, having served as a DREAM mentor for 2 years during college and also as a student coordinator for the UBC Women in Engineering Program during grad school. In addition to outreach, she is a strong proponent of effective teaching and learning practices in STEM education.

Mr. David Daniels, DREAM - Achievement Through Mentorship

David is a Head Mentor for DREAM - Achievement Through Mentorship. He is currently entering his final year as an undergraduate at Rice University, where he is studying Cognitive Sciences and Education Policy.

\section{Ms. Imani O. Butler, Rice University}

Ms. Imani O. Butler is a Head Mentor in DREAM-Achievement through Mentorship and an undergraduate at Rice University studying Ecology and Evolutionary Biology.

\section{Dr. Brent C Houchens, Rice University}

Brent C. Houchens is the Founding Director of the DREAM-Achievement through Mentorship program. 


\title{
Exploring Motivations of Volunteer Undergraduate Head Mentors in Engineering Outreach to Underserved and Underrepresented K-12 Mentees
}

\begin{abstract}
The motivations of volunteer Head Mentors over the nine year history of DREAMAchievement through Mentorship are investigated. This engineering outreach program has impacted thousands of underserved, underrepresented high school mentees. The program focuses on high mentoring contact hours. Over 200 mentors, primarily undergraduate engineering students, have volunteered in DREAM and as of 2015 over 100 had completed their undergraduate degrees. Of these former mentors, 25 served as Head Mentors as of spring 2015. These Head Mentors oversee the program at each school, develop design projects, organize and direct the other mentors, suggest and implement new initiatives in the program, and carry out research on the outcomes and effectiveness of the program. The Head Mentors volunteer a particularly large amount of time over their commitment of at least 3 semesters. An adaptation of Clary and Snyder's Volunteer Functions Inventory (VFI) provides a quantitative indication of motivations indicating that volunteer Head Mentors are overwhelmingly motivated by the Values function, related to altruistic and humanitarian concern for others. Qualitative analysis of free response questions in the internally developed Mentors Self-Assessment Survey (MSAS) indicates that the Pre-existing Personal Values concept is responsible for this motivation. While other motivations are also important to the Head Mentors, this study indicates that the clearest way to identify dedicated volunteers is through measurement of their values instilled since childhood. Additionally, results of the qualitative analysis indicate that Head Mentors placed high importance on the concepts of Skills Development, Awareness/Impact and Interactions all experienced as part of their Head Mentoring roles. Most Head Mentors demonstrated increased satisfaction with their undergraduate education as a result of participation in DREAM, as measured by the External Application concept. Surprisingly, the concept of Emotional Gain, including categories such as personal fulfillment, self-confidence, and satisfaction associated with mentoring rarely appeared in responses.
\end{abstract}

\section{Introduction}

Research has explored motivations associated with volunteerism in a broad sense for approximately 40 years (Esmond \& Dunlop 2004). The late-1980's and early 1990's showed a large endorsement of student volunteerism and community service from American colleges and universities. The U.S. government encouraged universities to embrace the service-learning link to enhancement of the educational experience as part of the National Community Service Act of 1990. The academic and social benefits of student volunteerism have been recognized for roughly three decades (Astin 1985), which has led an increasing number of higher education institutions to establish numerous community service and service learning offices on their campuses (Hall 2005; Ellis 1978; Enos 2002).

To increase participation in volunteer activities many universities have adopted mandatory approaches such as including community service hours in graduation requirements. However, research has shown mandatory volunteer work impedes long-term and impactful service learning; instead, voluntary approaches to increase community service for college campuses are more effective at creating an enriching service learning experience (Stukas et al. 1999). While a voluntary participation model may ultimately be more beneficial to the university, it presents a new difficulty, namely, recruitment (Enos 2002; Garver 2009). More research needs to be 
allocated towards discovering the mechanisms necessary for increasing and retaining student participation.

Though community service is often associated with altruism toward a community, studies have identified other factors that motivate people to volunteer: for example, developing a sense of purpose (Richey et al. 2015), interacting with others (Sergent \& Sedlacek 1990; Henderson 1981), or improving one's status and marketability (Peterson 2004; Wymer Jr. 2003). Since some motivations, like gaining work experience, have been found to correlate with volunteer age (Gidron 1987 in Esmond \& Dunlop 2004), results from studies on older adults cannot necessarily be extrapolated to teenagers and young adults. More research is needed to identify the motivations of undergraduate student volunteers specifically, in order to improve recruitment and retention (Clary, Snyder \& Ridge 1992; McCurley \& Lynch 1994; Esmond 2001).

This work analyzes the motivations, values, and personal outcomes of volunteer mentors for DREAM, a STEM outreach program, focusing in particular on mentors' reasons for joining this organization and what they gained from the experience.

\section{Background on DREAM and Related Volunteer Service Programs}

DREAM-Achievement through Mentorship strives to increase the number of underrepresented minority students and women pursuing post-secondary degrees, particularly in STEM fields. Undergraduates from Rice University volunteer to mentor small groups of Houston, Texas high school and middle school students weekly on semester-long engineering design challenges. Most DREAM mentors are engineering students. DREAM currently works with six high schools and one middle school. These include traditional public schools, public charter schools, and an all-girls preparatory school, and serve almost exclusively low-income minority students. Throughout the semester, mentors teach basic engineering and physics concepts, discuss higher education (including the college application process, financial aid, the benefits of college, and STEM-related fields of study), and develop relationships with their mentees on an individual level. The semester concludes with DREAM Day, when all participating mentees visit Rice University for a day to test their designs, tour campus engineering facilities, and ask questions of a student panel about the college experience. Mentors do not receive payment or course credit for their time, nor do they fulfill any university requirement by participating.

This study focuses specifically on the motivations of the student organizers of DREAM, known as Head Mentors. In addition to leading the mentoring sessions, Head Mentors also attend weekly planning meetings, recruit and assign mentors to specific school mentorship sessions, manage the logistics of transportation and school communication, and plan DREAM Days for each school. Accordingly, the number of volunteer hours that Head Mentors devote to the program is substantially larger than that of the mentors. Over the course of their tenure (at least 3 semesters), the average Head Mentor dedicates 200-600 hours to DREAM, and some even surpass 1000 hours. Understanding what drives these Head Mentors to voluntarily contribute such a significant amount of time to the organization would help to develop more effective strategies for recruiting and retaining future volunteers. The results of this work suggest that Head Mentors are predominantly influenced by personal, pre-existing value systems that align with the mission of the program.

\section{Methods}

The twenty-five former Head Mentors, who graduated between 2008 and 2015, were surveyed. The respondent pool included 11 women and 14 men. Thirteen self-identified as 
being from groups underrepresented in science and engineering (Hispanic, African American and Native American). The response rate of former Head Mentors was $100 \%$.

Two instruments were used to assess former Head Mentors' motivations for volunteering: Clary and Snyder's Volunteer Functions Inventory (VFI), which was adapted for use with DREAM Mentors, and an internally-developed Mentors Self-Assessment Survey (MSAS). Both contain quantitative components in the form of Likert scale questions; the MSAS also contains free response items. The analysis presented in this paper includes a quantitative portion, based on the VFI data, and a qualitative portion, based on the MSAS free responses.

\section{Historical Development of the Volunteer Function Inventory (VFI)}

Smith created a two-factor model for analyzing volunteer motivation between altruistic and egotistic motives (Smith 1981). Several other studies used similar two or three factor models to analyze volunteer motivation throughout the 1980's (Frisch \& Gerrard 1981; Gillespie \& King 1985; Morrow-Howell \& Mui 1989). Unfortunately, the research showed some limitations, and many studies lacked empirical evidence and recorded small sample sizes.

After extensively reviewing literature related to volunteer motivations, Cnaan and GoldbergGlen noted limitations of previous studies. They criticized previous research as predominantly descriptive. They also found weaknesses in the two or three-factor model because of the lack of widespread usage. Through factor analyses, Cnaan and Goldberg-Glen found that most motives grouped to one factor, suggesting a unidimensional scale. (Cnaan \& Goldberg-Glen 1991).

However, the unidimensional scale was soon challenged by multifactor models. Clary and Snyder found that different volunteers have different motivations for volunteering, and that one volunteer can have several motivations (Clary \& Snyder 1999: 157). They developed the Volunteer Functions Inventory (VFI) to identify the extent to which 6 sources of motivation, known as "functions" (Values, Understanding, Career, Social, Enhancement, and Protective), have the greatest influence on an individual volunteer. The VFI has been demonstrated to have a high degree of internal consistency and stability (Clary \& Snyder 1999: 157).

\section{Adapted Volunteer Functions Inventory (VFI)}

The VFI has been adapted for use with DREAM mentors and Head Mentors, and was shown to be internally consistent in a previous study (Bautista-Chavez et al. 2012). The adapted version used for this study is included in the Appendices.

The VFI contains a total of 48 items. Items 1-47 are statements, and respondents are asked to indicate, on a numerical Likert scale, the extent to which they agree with each statement, where 1 is "strongly disagree" and 7 is "strongly agree". Each of these 47 items falls into one of three categories: Motivation, Outcomes, and Satisfaction. All of the items in the Motivation and Outcomes categories correspond to one of the six functions (Career, Social, Values, Understanding, Enhancement and Protective). The VFI functions are briefly defined in Table 1.

Of the 48 items, 5 are dedicated to each Motivation function and 2 determine each Outcomes function. The Satisfaction category consists of 5 items that do not correspond to a specific function. No information pertaining to the section or function with which each question was associated was provided to the respondents. Item 48 is a multiple-choice question that asks respondents to indicate their anticipated long-term volunteering involvement. The responses to this question are not reported here because the amount of time between graduation and survey completion varied among respondents. 
Table 1. Brief definitions of the six VFI functions.

\begin{tabular}{ll}
\hline \hline Function & Brief Definition \\
\hline Values & Expression of altruistic and humanitarian values \\
\hline Understanding & Desire to learn about the world and develop abilities and skills \\
\hline Enhancement & Enhancement of personal sense of esteem and growth \\
\hline Social & Conforming to the influence of significant others \\
\hline Career & Exploration of job opportunities or gain of career-related experience \\
\hline Protective & Escape from negative feelings, such as guilt, to address personal problems \\
\hline \hline
\end{tabular}

It is also relevant to note that previous work investigated the use of the Volunteer Motivation Inventory (VMI) created by Esmond and Dunlop (2004) to study current and former DREAM mentor motivations, where the distinction between Head Mentors and mentors was not considered (Bautista-Chavez et al. 2012). The VMI consists of 44 items to which volunteers respond using a 5-point Likert scale and identifies ten key motivational categories. Six map directly to the VFI functions and the remaining four are Reciprocity, Recognition, Reactivity, and Social Interaction. It was found that removing the extra functions introduced by the VMI results in a ranking of remaining functions in the same order of importance as measured by the VFI. Thus, only the VFI was used in the current work.

\section{$\underline{\text { VFI Analysis }}$}

Average Motivations and Outcomes scores for each function were calculated both for individual respondents and the group overall, as well as average satisfaction scores. The subsequent analysis focuses on Motivation scores. All items were worded such that higher numbers corresponded to a stronger influence of the function on a respondent's volunteer experience. Thus, scores greater than 4 (neutral) indicate that the function did have an impact on the respondent's motivation for volunteering, while scores less than 4 indicate that the function did not have a substantial impact.

A between-subjects analysis as well as a within-subjects analysis were conducted on the responses to the VFI items. For the between-subjects analysis, one-sided t-tests using group means were used to evaluate whether each function had a significant influence on the Head Mentors' motivation $\left(\mathrm{H}_{0}: \mu \leq 4\right)$. For the within-subjects analysis, a one-way, repeated-measures ANOVA was conducted to evaluate the relative influence of each function on individuals. $P$ values less than 0.05 were considered statistically significant.

\section{Mentors Self-Assessment Survey (MSAS)}

The MSAS is designed to provide direct responses from the Head Mentors about their selfidentified outcomes, and also to better understand how their backgrounds and perceptions may have influenced their motivations and outcomes. It was developed internally and draws from surveys from other researchers such as Yowell et al. 2013. It contains both quantitative and qualitative items in the form of Likert scale questions and free response sections. A copy is included in the Appendices.

The quantitative items include statements about the Outcomes from Participation in DREAM and about Background and Perceptions on Educational Equality. Most of the items also include a free response section, where respondents could elaborate on their numerical score. These free- 
responses allowed subtleties in motivations and outcomes to be uncovered, with some consideration for the backgrounds of each respondent.

\section{MSAS Analysis}

Free response items were coded using an open-coding procedure by three researchers. Each first independently proposed high-level concepts. These were molded into six final concepts which the researchers mutually agreed included all proposed concepts. The concepts and categories (including keywords and phrases) are listed in Table 2.

The concept of External Applications includes increases in educational satisfaction as a result of serving as a Head Mentor or mentor and valuation of mentoring and outreach in areas outside of DREAM, such as a mentoring program offered by an employer or future employer. The Skills Development concept includes the creation, exercising or improving of skills such as communication, research, teaching and leadership. It also includes solidification or expansion of content knowledge in math, physics and engineering due to the need to teach the mentees. Pre-existing Personal Values are societal values that Head Mentors had before participating in DREAM and include existing societal passions, interests and values, the desire to make a difference and a valuation of equality for all people. This is distinguished from other concepts in that it was clearly identified as pre-existing. The last three concepts are related to gain or enjoyment which is not directly skills or academic content and include Awareness Gain, Emotional Gain and Interpersonal Interactions. Awareness Gain includes improved understanding of cultural or socioeconomic issues and a sense of alignment with the goals of DREAM to improve opportunities and educational literacy of underserved communities. Emotional Gain includes the satisfaction from mentoring, personal fulfillment, increase in self-confidence and rewarding feelings. Finally, Interpersonal Interactions describes satisfaction found in interactions with mentors, mentees and school staff, and in forming friendships and a network. All of the freeresponses on the MSAS were coded to these six concepts.

Table 2. Concepts and Categories from the MSAS open-coding.

\begin{tabular}{ll}
\hline \hline Concepts & Categories \\
\hline External Applications & $\begin{array}{l}\text { Educational satisfaction, outreach, mentoring (in career), recruiting (for } \\
\text { employer), real-world (application of coursework or as part of career) }\end{array}$ \\
\hline Skills Development & $\begin{array}{l}\text { Research, content knowledge (solidification, refresh), written communication, } \\
\text { oral communication, teaching or explaining, teamwork, leadership, } \\
\text { diplomacy, planning, management (time and people), organization }\end{array}$ \\
\hline Pre-Existing Personal Values & $\begin{array}{l}\text { Pre-existing societal passions, interests, understanding or values, valuation of } \\
\text { education, desire to make a difference, do something good or help the } \\
\text { community, pre-existing valuation of equality }\end{array}$ \\
\hline Awareness Gain & $\begin{array}{l}\text { Learning about an issue or social injustice or inequality, improving cultural } \\
\text { understanding, different backgrounds, having an impact or purpose, new } \\
\text { perspectives, policy, exposure, opportunities, expansion, educational literacy }\end{array}$ \\
\hline Emotional Gain & $\begin{array}{l}\text { Personal fulfillment, perceived impact, satisfaction, empowerment, positive } \\
\text { influence, building self-confidence, relieved stress, inspired }\end{array}$ \\
\hline Interpersonal Interactions & $\begin{array}{l}\text { Professional, personal, interacting with Head Mentors or school staff, } \\
\text { interacting with mentors (motivating, community) or mentees (engaging, } \\
\text { motivating, inspiring, advising), friendships, relationships, network }\end{array}$ \\
\hline \hline
\end{tabular}


It should be noted that two of the three researchers who coded the MSAS were not familiar with the VFI. These two independently concluded that Pre-existing Personal Values should be a category. That this category maps almost perfectly to the Values function in the VFI suggests how clearly the theme of Head Mentors' values is exposed in the data.

\section{Results \& Discussion}

Results are presented first from the VFI quantitative analysis and then from the MSAS qualitative analysis. The mutual interactions observed between the VFI and MSAS are then described in the Interpretations subsection.

\section{$\underline{\text { VFI Results }}$}

The notation $m_{F}$ and $o_{F}$ refers to an individual respondent's Motivations and Outcomes scores, respectively, for function $F$ (where $F$ can refer generally to any of the functions, or can be replaced by $C, S, V, U, E$ or $P$ to specify the Career, Social, Values, Understanding, Enhancement or Protective function). The mean group values, averaged across all respondents, are represented with the notation $M_{F}$ and $O_{F}$ for Motivation and Outcomes, respectively.

In both the between-subjects and within-subject analyses, the Values and the Understanding functions rank number one and two as the most significant influencers for Head Mentors.

VFI Between-Subjects Analysis

Mean function scores and standard deviations across all respondents are presented in Table 3 and Figures 1 and 2. Based on aggregated group averages across respondents, the functions rank from highest to lowest as Values, Understanding, Enhancement, Social, Career, and Protective.

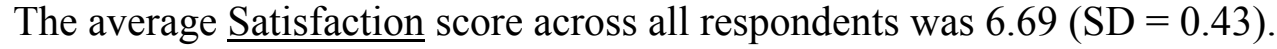

Table 3. Mean function scores and standard deviations for Motivations and $\underline{\underline{\text { Outcomes }}}$ between-subjects.

\begin{tabular}{lcccccc}
\hline \hline & Career & Social & Values & Understanding & Enhancement & Protective \\
\cline { 2 - 7 } & 3.23 & 3.88 & 6.27 & 5.19 & 4.01 & 3.06 \\
Mean Motivation & $(1.53)$ & $(1.28)$ & $(0.84)$ & $(1.23)$ & $(1.34)$ & $(1.26)$ \\
scores, $\boldsymbol{M}_{\boldsymbol{F}}$ (SD) & & & & & & \\
Mean Outcome & 3.78 & 5.62 & 6.36 & 5.66 & 4.52 & 3.12 \\
scores, $\boldsymbol{O}_{\boldsymbol{F}}(\mathrm{SD})$ & $(1.70)$ & $(1.47)$ & $(0.78)$ & $(1.29)$ & $(1.52)$ & $(1.78)$ \\
\hline \hline
\end{tabular}




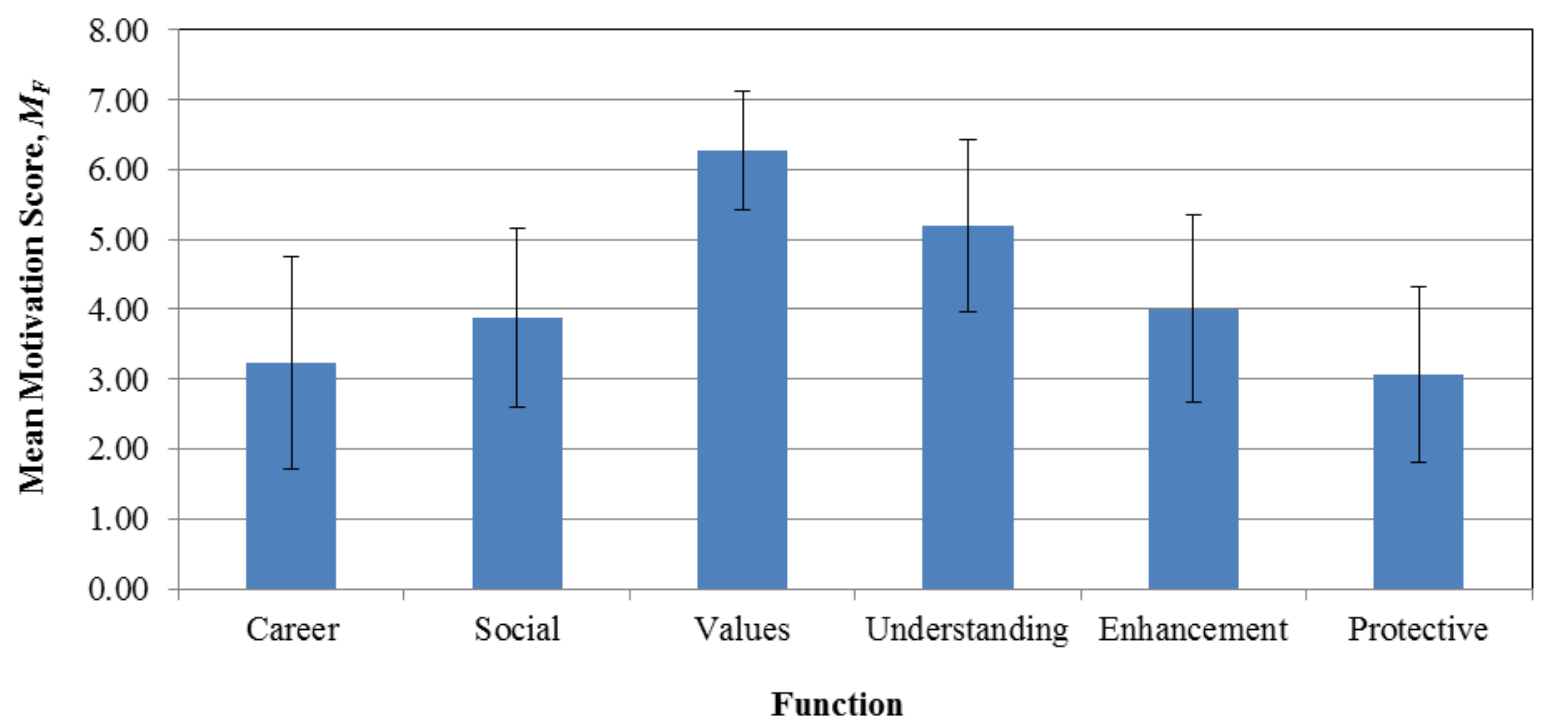

Figure 1. Mean Head Mentor Motivations scores from the VFI, averaged across respondents. Error bars show standard deviations.

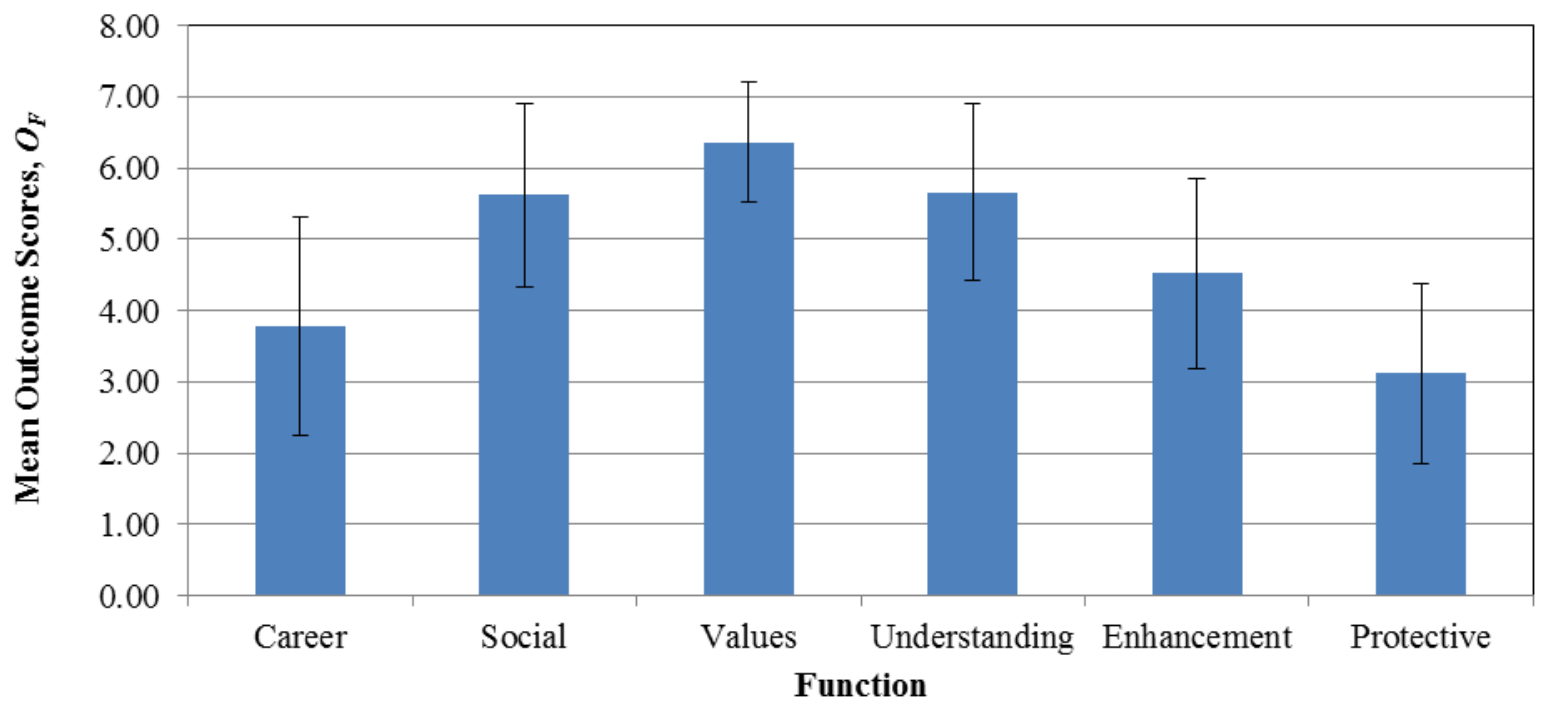

Figure 2. Mean Head Mentor Outcomes scores from the VFI, averaged across respondents. Error bars show standard deviations.

Only the three highest ranked functions have group means greater than 4 (neutral). These means are $M_{V}=6.27$ (Values), $M_{U}=5.19$ (Understanding) and $M_{E}=4.01$ (Enhancement). Only the Values and Understanding function means were significantly greater than 4 (Values: $\mathrm{H}_{\mathrm{A}}: \mu>$ 4; $\mathrm{t}(24)=13.5, p<0.001$; Understanding: $\mathrm{H}_{\mathrm{A}}: \mu>4$; $\left.\mathrm{t}(24)=4.8, p<0.001\right)$. This result implies that overall, the Head Mentors' motivations for participating in DREAM were most strongly influenced by the Values function - a desire "to express or act on important values, such as humanitarianism and helping the less fortunate," - and the Understanding function - a desire "to learn more about the world, and/or exercise skills that are unused" (Clary et al. 1998). 


\section{VFI Within-Subject Analysis}

The overall results of the ANOVA were statistically significant $(\mathrm{F}(5,120)=41.25, p<$ 0.001; Huynh-Feldt epsilon $>0.95)$. Repeated paired t-tests with a Bonferroni correction were used for post-hoc testing. Average within-subject differences between function pairs were calculated as mean $\left(m_{F 1}-m_{F 2}\right)=M_{F 1}-M_{F 2}$. These values are represented with the notation $\triangle M_{F 1-F 2}$ and are shown in Table 3. Most of the differences were significant, with many well below $p<0.001$. In Table 4 , the direction of subtraction was chosen such that positive differences result from higher scores for the function in the corresponding row than in the corresponding column. For example, if an individual respondent's Enhancement score, $m_{E}$ were known, one would expect their other function scores to be approximately as follows: Values $=$ $m_{E}+2.27$; Understanding $=m_{E}+1.19 ;$ Social $=m_{E}-0.13 ;$ Career $=m_{E}-0.77$; and Protective $=$ $m_{E}-0.94$. Statistically significant differences, as determined with the post-hoc t-tests, are indicated with an asterisk. These differences between function pairs are depicted graphically in Figure 3.

Table 4. Average within-subject differences between function pairs.

$$
* p<0.05
$$

\begin{tabular}{lcccccc}
\hline \hline & Career & Enhancement & Protective & \multicolumn{2}{c}{ Social } & \multicolumn{2}{c}{ Understanding } & Values \\
& $\Delta M_{F-C}$ & $\Delta M_{F-E}$ & $\Delta M_{F-P}$ & $\Delta M_{F-S}$ & $\Delta M_{F-U}$ & $\Delta M_{F-V}$ \\
\cline { 2 - 7 } Career $\Delta M_{C-F}$ & $(0)$ & -0.77 & 0.17 & -0.65 & $-1.96^{*}$ & $-3.04^{*}$ \\
Enhancement $\Delta M_{E-F}$ & 0.77 & $(0)$ & $0.94^{*}$ & 0.13 & $-1.19^{*}$ & $-2.27^{*}$ \\
Protective $\Delta M_{P-F}$ & -0.17 & $-0.94^{*}$ & $(0)$ & -0.82 & $-2.13^{*}$ & $-3.21^{*}$ \\
Social $\Delta M_{S-F}$ & 0.65 & -0.13 & 0.82 & $(0)$ & $-1.31^{*}$ & $-2.39^{*}$ \\
Understanding $\Delta M_{U-F}$ & $1.96^{*}$ & $1.19^{*}$ & $2.13^{*}$ & $1.31^{*}$ & $(0)$ & $-1.08^{*}$ \\
Values $\Delta M_{V-F}$ & $3.04^{*}$ & $2.27^{*}$ & $3.21^{*}$ & $2.39^{*}$ & $1.08^{*}$ & $(0)$ \\
\hline \hline
\end{tabular}

Similar to the between-subject results, the Values and the Understanding functions rank as the strongest influencers on Head Mentors' motivation for volunteering. The differences between Values and the Understanding are statistically significant compared to each other, and are also statistically different when either function is compared to all of the others. As influencers these are followed by Enhancement, Social, Career, and Protective, although the only statistically significant difference among these four functions is between Enhancement and Protective.

It is important to emphasize that the ANOVA results reflect trends in the relative impact of the functions on the average respondent: specifically, that the Values score for the average DREAM Head Mentor was greater than their scores in the other functions. This does not in itself indicate that the Values scores were necessarily high enough to be considered a principal source of motivation.

However, the data do suggest that this is the case when the within-subject analysis is considered in light of the between-subject analysis. For the Values and the Understanding functions, the group (between-subject) means were high (6.27 and 5.19, respectively) and statistically significantly greater than 4 , and within-subject, the scores were significantly greater than the other functions. The combination of these results suggests that the DREAM Head Mentors are both strongly and predominantly motivated by the Values and Understanding functions. 

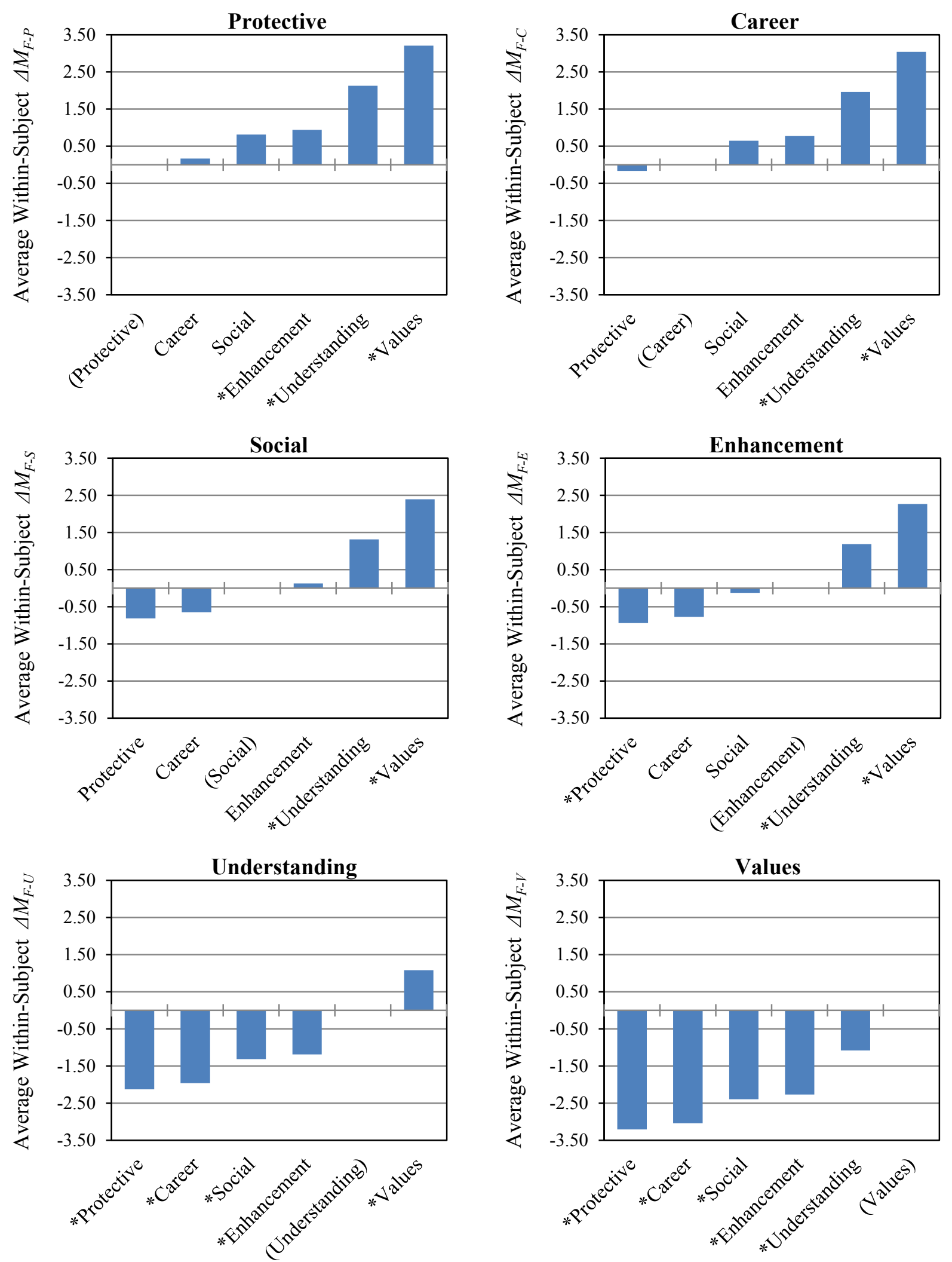

Figure 3. Average within-subject differences, $\Delta M$, between one function and the other five. Vertical axis values are differences relative to the specified function; positive values indicate that the comparison functions scored higher than the specified function. Statistically significant differences indicated by $*$ are based on post-hoc t-tests, $p<0.05$. 


\section{MSAS Results}

The concepts and categories were used to code the free response questions from the MSAS. Natural item groupings resulted from comparing the number of references to each concept across items. The results are presented in these groupings for clarity, with all scaled to the maximum number of references. It should be noted that no Head Mentors indicated that they participated in DREAM to fulfill a service requirement (item MSAS-7).

\section{Skills Development}

MSAS items 1, 2 and 3 focus on oral communication, written communication and fundamental engineering skills, respectively. These items group naturally via concepts referenced (through categories) and are shown in Figure 4. Not surprisingly, the categories in the Skills Development concept were the most often referenced in these items. Negative references such as "did not help my" skills were only significant for MSAS-2. Even though every Head Mentor in this cohort participated in some external publication, presentation or poster presentation, not all were involved in the actual writing. Some instead were involved in data analysis and thus did not indicate an increase in written communication skills. An insignificant number of negative references appeared for MSAS-1 and MSAS-3 (1 and 3 instances, respectively). Oral communication dominated the skills development.

The frequency of references to increased engineering skills were surprisingly high, even considering that the DREAM projects are design-based. This is a particularly relevant finding for engineering schools, where the value of such outreach programs on subject-matter knowledge might be overlooked. Additionally, it will next be shown in the subsequent two subsections that the External Application of engineering experienced through DREAM was an important part of Head Mentors' satisfaction with their education and will continue to play an important role in their future career paths and volunteer participation.

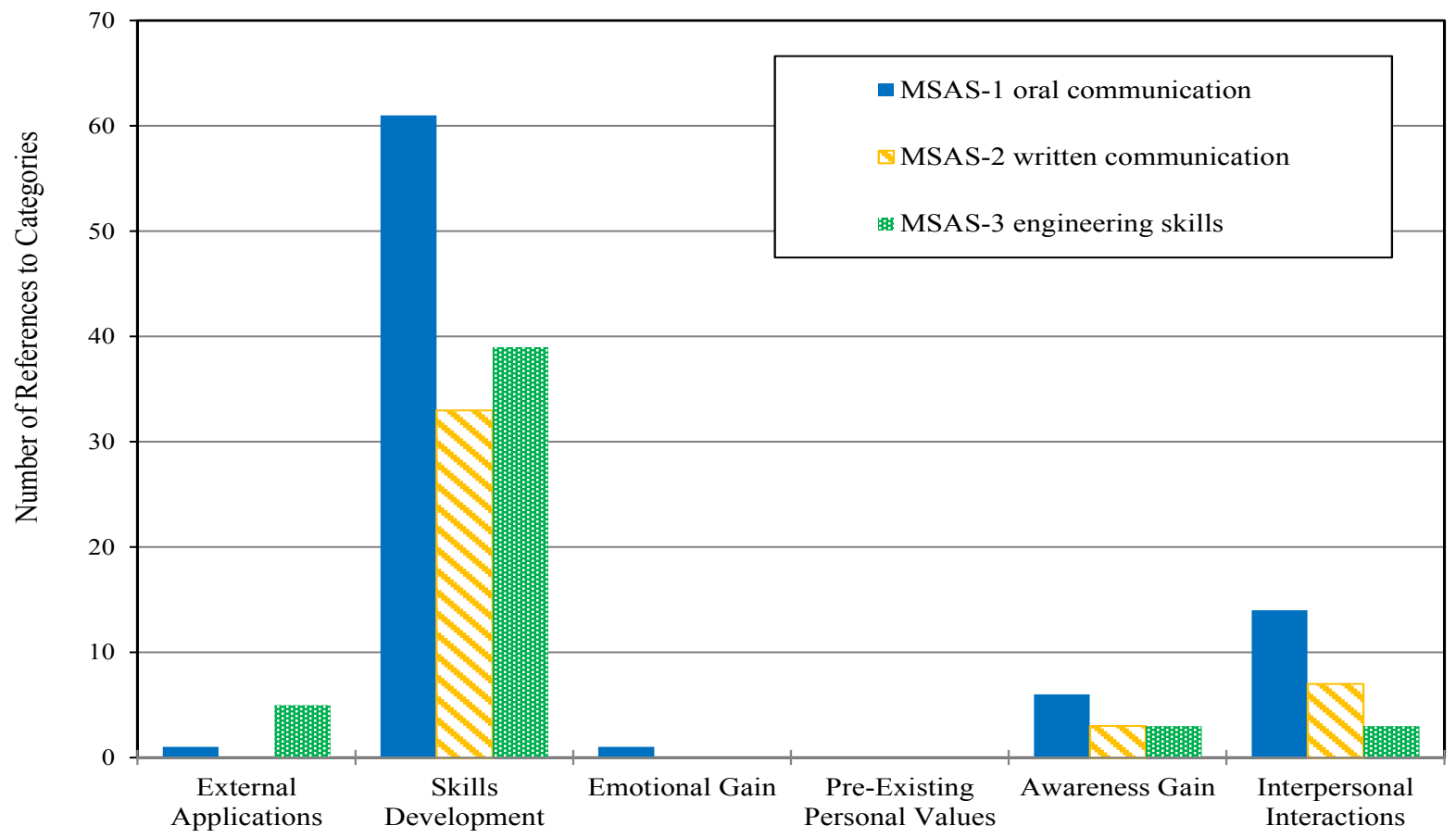

Figure 4. Number of references to categories within the concepts for items 1,2 and 3 on the MSAS. 


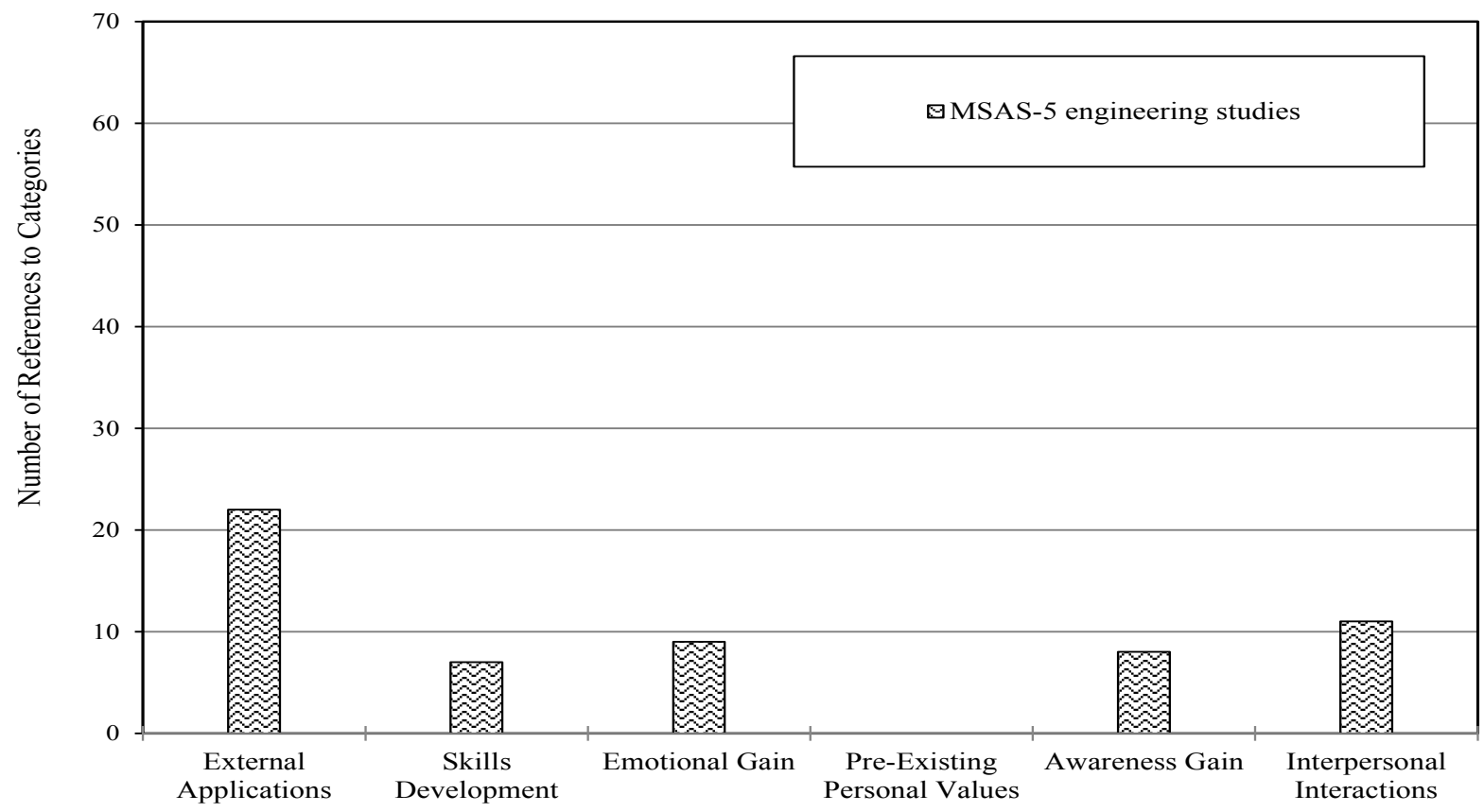

Figure 5. Number of references to categories within the concepts for item 5 on the MSAS.

\section{Enhancement of Engineering Studies}

From an engineering education standpoint, item MSAS-5 is perhaps the most interesting. Here the 3 non-engineering Head Mentors were removed due to the nature of the question "Participating in DREAM impacted my satisfaction with my engineering studies." The remaining former Head Mentors responses are shown in Figure 5. Every concept except that of Pre-Existing Personal Values, which is only scored for statements reflecting on events previous to participation in DREAM, was indicated.

Head Mentors indicated enhancement of their engineering studies through: a real-world application (External Applications); improved communication skills, writing skills and content knowledge (Skills Development); inspiration, satisfaction and a creative outlet (Emotional Gain); engagement in the community (Awareness Gain); and interactions with other Head Mentors and mentees (Interpersonal Interactions). It should be noted that there were 6 negative responses appearing in External Applications and 1 negative response in Skills Development. The benefits of community engagement to engineering education are certainly real and quantifiable, at least for this cohort. This not only provides a justification for investing in such service learning and community engagement opportunities, but can also be seen as a retention mechanism for undergraduates in engineering.

\section{Influence on Future Plans}

Items MSAS-4 "My experience with DREAM impacted my future career plans (after graduation)" and MSAS-16 "My volunteering experience with DREAM affected/will affect my current/future volunteering organization choice" naturally group as they both relate to future plans. The results of coding the free responses to these items are shown in Figure 6. In both items the focuses on External Applications and Awareness Gains are clearly indicated. This suggests that Head Mentors place high importance on social justice and cultural awareness issues and will be more attracted to volunteer opportunities and employers that also consider these issues. In External Applications, 8 negative responses were indicated on MSAS-4, indicating that External Applications are not universally important to the Head Mentors in their careers. 


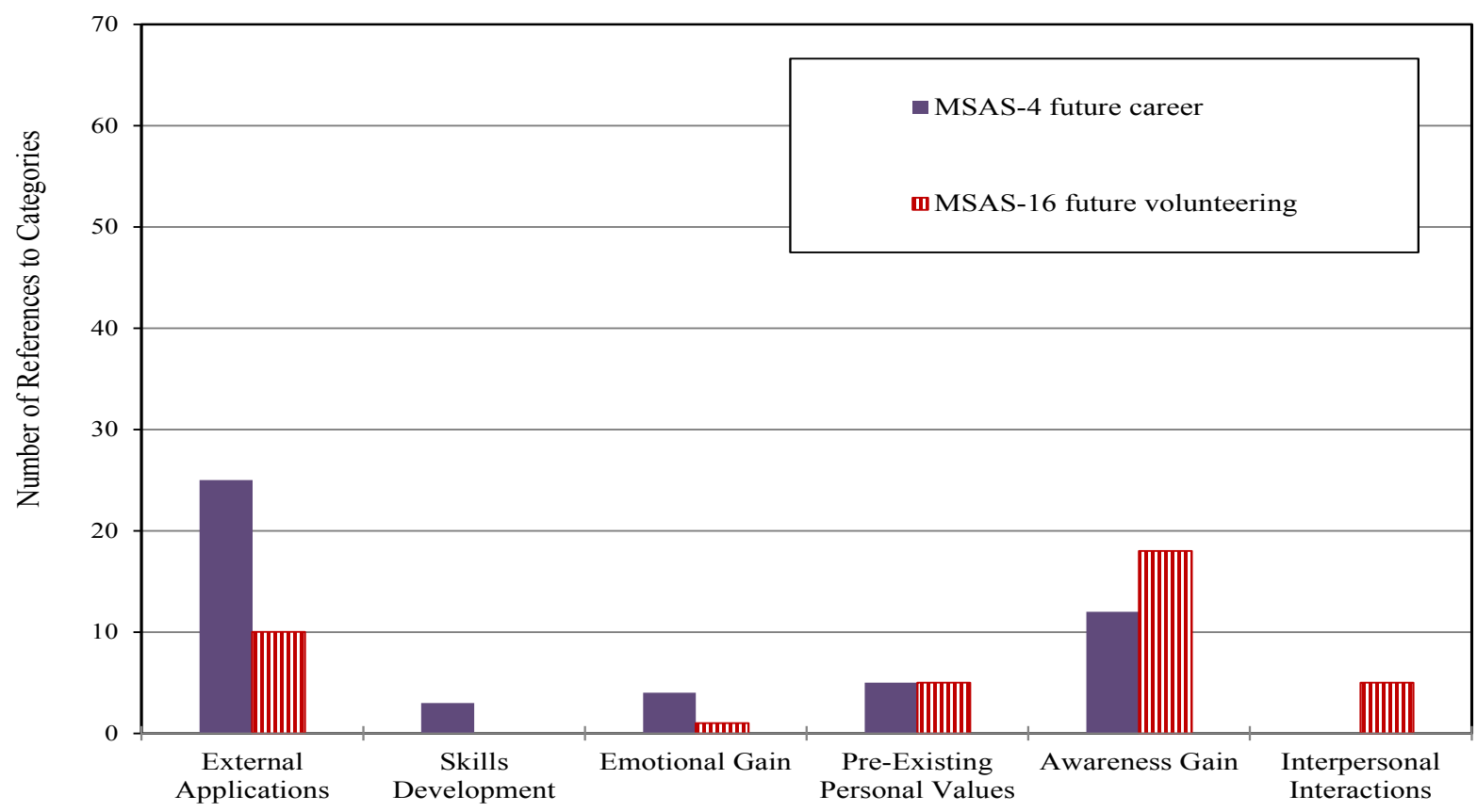

Figure 6. Number of references to categories within the concepts for items 4 and 16 on the MSAS.

\section{Evidence of Strong Pre-Existing Personal Values}

Item MSAS-17 asks "What is your view on the education disparity facing underserved and underrepresented communities?". The Head Mentors overwhelmingly cited Pre-Existing Personal Values in response to this question, but also indicated strong Awareness Gain, as shown in Figure 7. The Head Mentors seem to largely have been instilled with values consistent with the mission of DREAM before their involvement. This suggests a strategy for recruiting and retaining dedicated volunteers - seek those with already aligned values. They were also able

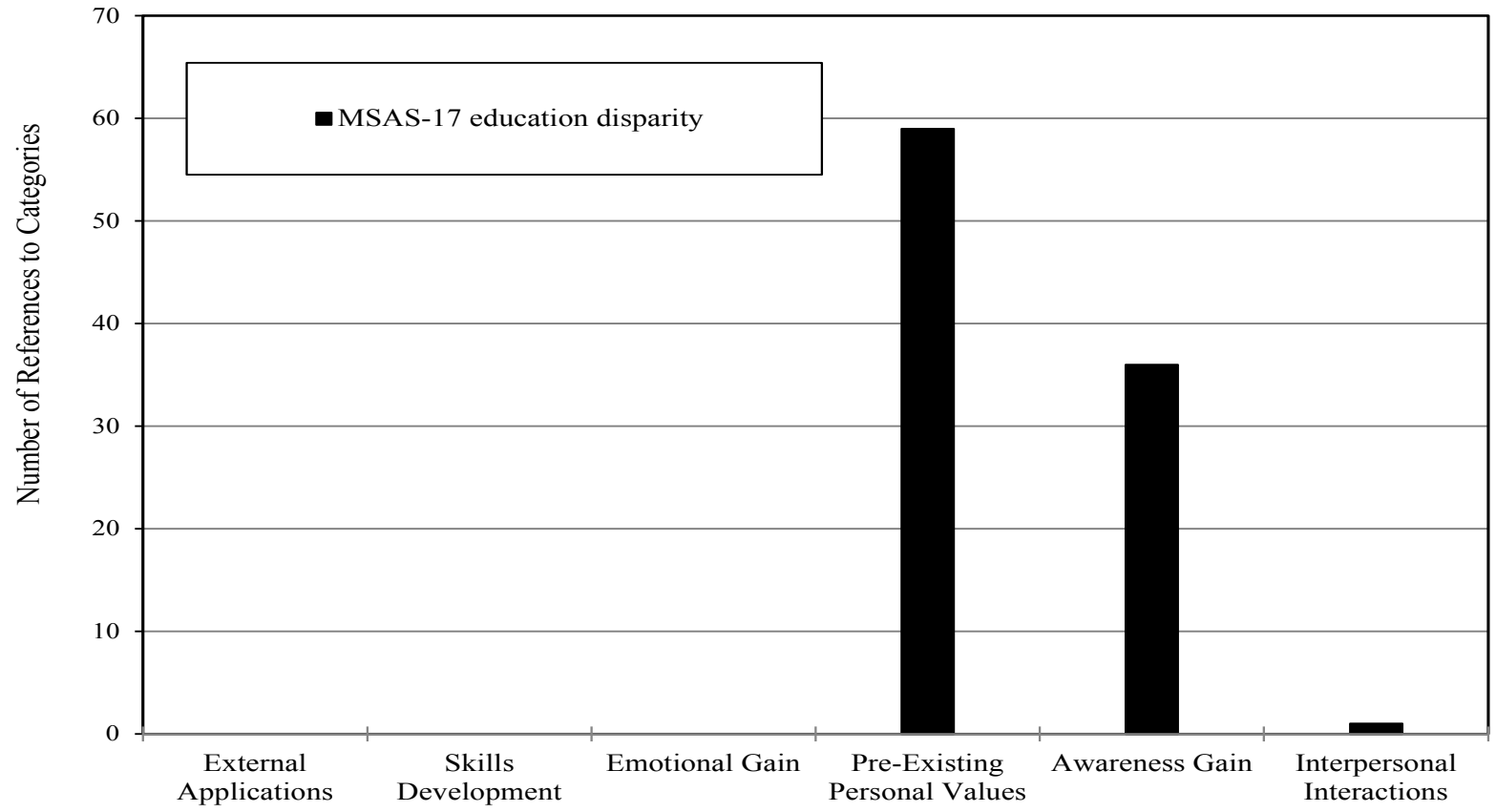

Figure 7. Number of references to categories within the concepts for item 17 on the MSAS. 
to better their awareness of social injustices through participation. This indicates that the best volunteers need not already be fully aware of the extent of socioeconomic disparities. Further, gaining this awareness may correlate well with high retention.

\section{Greatest Benefit}

The final qualitative sample of interest is from item MSAS-8. This purely free-response question asks "What is the greatest benefit that you feel you got out of participating in DREAM?" It was expected that this question would garner the most references to Emotional Gain. The number of references to Emotional Gain (16) were significant, but these were spread over only 9 of the 25 respondents. The exact same was true for Awareness Gain. In comparison, the 22 references to Interpersonal Interactions came from 16 respondents. This high valuation on Interpersonal Interactions was not expected compared to the more tangible concepts of Emotional Gain and Awareness Gain. These results are shown in Figure 8.

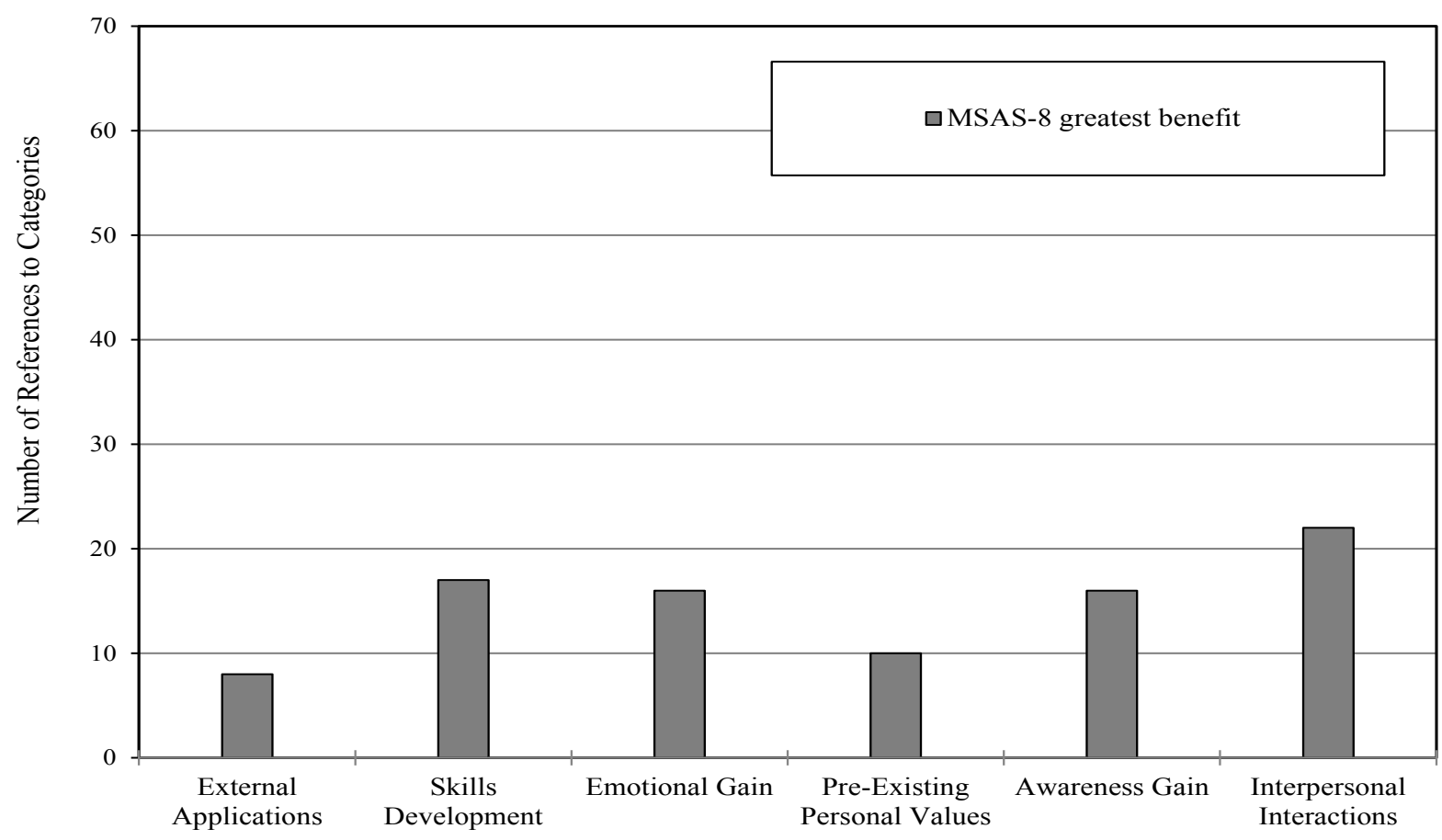

Figure 8. Number of references to categories within the concepts for item 8 on the MSAS.

\section{Interpretations}

The MSAS free-response questions proved very useful for interpreting the quantitative VFI findings. Because an open-coding strategy was used in the qualitative analysis of the MSAS data, the resulting concepts did not map one-to-one to VFI functions. However, many of the concepts related to at least one function. An approximate mapping is given in Table 5. To generate this mapping it is not sufficient to consider only the brief definitions of the VFI motivations functions. Instead, coding the VFI questions using the MSAS concepts produces the most relevant mapping.

It is first worth noting that no MSAS concepts that naturally map to the VFI Social function appeared naturally from the free response data. This is consistent with the finding that the Social 
function was the third from the least motivational function to the Head Mentors. Recall that the Social function describes "conforming to the influence of significant others".

The Career function also does not map to a MSAS concept, primarily because none of the MSAS free responses indicated intent of "gaining career-related experience". When careerrelated Skills Development or External Applications were indicated, it was the result of a coincidence rather than a goal. An argument could be made that the Protective function is at least slightly related to the Emotional Gain concept. However, close inspection of the questions that make up the Protective function show little relevance to those codes that incorporated into the Emotional Gain concept. The Protective function indicates need for an escape or reduction of guilt, neither of which were indicated in the MSAS responses. The Protective and Career functions are the lowest and second lowest motivations to the Head Mentors based on the averages across participants of VFI scores.

The VFI functions Values, Understanding and Enhancement were each represented either completely or partially by the MSAS concepts. Of these, the loosest mapping is Interpersonal Interactions to Enhancement, as most of the relationships mentioned in the MSAS free response were that of mentor-mentee or colleague, rather than friend. Certainly few Head Mentors appear to have joined with the intent to expand their friend group.

Table 5. MSAS concept to VFI function mapping, where neither are typically fully inclusive of the other.

\begin{tabular}{lll}
\hline \hline MSAS Concepts & Relevant VFI Function & Explanation of VFI Relevance \\
\hline $\begin{array}{l}\text { External } \\
\text { Applications }\end{array}$ & Some of Understanding & Relates to "exercise skills that are often unused" \\
\hline $\begin{array}{l}\text { Skills } \\
\text { Development }\end{array}$ & Some of Understanding & Relates to “exercise skills that are often unused" \\
\hline $\begin{array}{l}\text { Pre-Existing } \\
\text { Personal Values }\end{array}$ & All of Values & Nearly perfect one-to-one match \\
\hline $\begin{array}{l}\text { Awareness Gain } \\
\text { Emotional Gain }\end{array}$ & Most of Understanding & Relates to "seeking to learn more about the world" \\
\hline $\begin{array}{l}\text { Interpersonal } \\
\text { Interactions }\end{array}$ & Little of Enhancement & Relates to "makes me feel needed" \\
\hline \hline
\end{tabular}

\section{Conclusions and Future Work}

The combination of the quantitative VFI analysis with the qualitative MSAS open-coding analysis produced important findings about the chronology of the motivations of Head Mentors. The dominance of the Values function in Head Mentors motivations appears to be explained predominantly by Pre-Existing Personal Values that they held before participation in DREAM. This suggests that an effective approach to recruiting the most dedicated volunteer leaders for both DREAM and other community engagement organizations would be to appeal to their values. Note that this does not imply that potential volunteers who score low on Values should be excluded from volunteering. A comparison with DREAM Mentors who did not serve as Head Mentors is warranted, to determine if scoring high on the VFI Values function was universal to 
all mentors or was weighted preferentially toward those who sought the Head Mentor leadership position.

DREAM and similar organizations would be well served by recruiting volunteers with PreExisting Personal Values. Qualitative analysis suggests that this Values motivation is influenced heavily by family and personal experiences, and several participants reported that shared childhood experiences helped them both empathize with their mentees and better understand the positive impact of their volunteer work. Thus, community engagement programs may benefit from expanding their recruitment efforts to target potential volunteers with backgrounds similar to those of the target community. For example, a volunteer organization aiming to encourage underserved high school students to attend college might approach first-generation college students as potential volunteers, and measure their Pre-Existing Personal Values to help identify leaders.

The second highest VFI motivation of Understanding breaks into three MSAS concepts for Head Mentors: External Applications, Skills Development and Awareness Gain. All three concepts are attractive to producing more well-rounded, skilled and socially aware engineering students who find greater satisfaction with their education, both directly and indirectly.

The most unexpected result that can't be explained from this work is the significance of Interpersonal Interactions to the Head Mentors. In particular, it would be interesting to explore if a subset of extroverted engineers are attracted to DREAM because it affords the opportunity for interactions with mentees. Alternatively, the Interpersonal Interactions could simply be a positive outcome for Head Mentors that they didn't expect. In the latter case, it would be interesting to understand if there is an energy barrier for mentors to attend their first mentoring session and to determine how mentors who persisted overcame that barrier. With this understanding, personality assessments of Head Mentors could provide useful insights and suggest strategies for recruiting.

\section{Further Impact and Recommendations for Other Programs}

A surprising result from this work was the contradiction to the assumption that college student volunteers are motivated by gaining professional experience when volunteering. This assumption is based on past findings that young volunteers tend to place higher value on work experience gained through volunteering when compared to other groups (Gidron 1987 in Esmond \& Dunlop 2004). This study found that this particular cohort of volunteers were instead primarily motivated by their personal values as well as a desire to interact with mentees and fellow volunteers, gain first-hand awareness of social issues, and develop skills that complement their (primarily) engineering education to help tackle these social issues. Similar community engagement programs should highlight motivational VFI functions such as Values and Understanding, and the MSAS concepts External Applications, Pre-Existing Personal Values and Interpersonal Interactions to attract committed, long-term volunteers and leaders.

Further research is needed to determine which motivations are more useful for recruitment versus retention. However, community engagement programs may benefit from integrating these key motivations into their current methods of recruitment. For example, instead of focusing on how volunteering with an organization will provide volunteers with valuable job experience, programs could suggest that volunteering will give them more satisfaction with their studies as they apply skills toward solving real-world social issues. Instead of advertising volunteering as simply an opportunity to socialize, community engagement programs could promote the social benefits of building meaningful relationships with mentees (or community 
members in general) and colleagues who share a passion for volunteering. Instead of vaguely describing their efforts for helping communities in need, programs could take more time to introduce the particular social issue they are addressing and discuss how this issue is affecting a certain community as well as the tangible ways prospective volunteers would be making a difference. Furthermore, consistently appealing to these types of motivational factors and repeatedly revisiting long-term program goals may help retain volunteers by acknowledging the humanitarian aspects of the program.

Not all committed volunteers will be motivated by the same factors, and some motivations might be more useful in initially attracting volunteers, while others aid retention. This study on DREAM's Head Mentors advocates the use of a balanced combination of these factors in recruitment efforts and organizational goals to establish a committed group of volunteers and leaders.

\section{Acknowledgements}

This work was supported principally by The Boeing Company. Additional program support for DREAM was provided by Shell and by the CH2M Hill Foundation.

\section{References}

Astin, A.A. (1985). Involvement: The cornerstone of excellence. Change. pp. 35-39.

Bautista-Chavez, A.M., Garza, A.N., Herkes, S.M., Kienast, K.J., McClendon, N.W., Sharpe, A.L. \& Houchens, B.C. (2012) Motivations of Volunteer DREAM Mentors, ASEE Paper AC 2012-3355, Proceedings of the 2012 ASEE Annual Conference \& Exposition, San Antonio, TX.

Clary, E.G., Snyder, M. \& Ridge, R. (1992). Volunteers' motivations: a functional strategy for the recruitment, placement, and retention of volunteers. Nonprofit Management and Leadership, 2, 333-350.

Clary, E.G, Snyder, M., Ridge, R.D., Copeland, J., Stukas, A.A., Haugen, J. \& Miene, P. (1998). Understanding and Assessing the Motivations of Volunteers: A Functional Approach, J. Personality and Social Psychology, 74(6).

Clary, E.G. \& Snyder, M.. (1999). The Motivations to Volunteer: Theoretical and Practical Considerations. Current Directions in Psychological Science. Volume 8: 156.

Cnaan, R.A., \& Goldberg-Glen, R.S. (1991). Measuring motivations to volunteer in human services. Journal of Applied Behavioral Science, 27, 269-284.

Enos, S. (2002). Service-learning on American campuses: Challenges for pedagogy and practice. Issues in Teaching and Learning, 1(2).

Ellis, S.J. (1978). American traditions of volunteerism and service-learning: The twentieth century. Szneraist, Spring, 37-39.

Esmond, J. (2001). Count me in! 501 ideas on recruiting volunteers. Perth: Newseason

Esmond, J. \& Dunlop P. (2004). Developing the Volunteer Motivation Inventory to Assess the Underlying Motivational Drives of Volunteers in Western Australia.

Frisch, M.B. \& Gerrard, M. (1981). Natural helping systems: A survey of Red Cross volunteers. American Journal of Community Psychology, 9(5), 567-579.

Garver, M.S., Divine R.L. \& Spralls, S.A. (2009) Segmentation analysis of the volunteering preferences of university students. Journal of Nonprofit \& Public Sector Marketing 21.1: 1-23.

Gillespie, D.F. \& King, A.E. (1985). Demographic understanding of volunteerism. J. Soc. \& Soc. Welfare, 12, 798.

Hall, P. Volunteerism, U.S. New Dictionary of the History of Ideas. 2005. 
Henderson, K.A. (1981). Motivations and perceptions of volunteerism as a leisure activity. Journal of Leisure Research, 13(3), 208.

McCurley, S. \& Lynch, R. (1994). Essential volunteer management. London: Directory of Social Change.

Morrow-Howell, N. \& Mui, A. C. (1989). Elderly volunteers: Reasons for initiating and terminating service. Journal of Gerontological Social Work,13(3-4), 21-34.

Peterson, D. K. (2004). Recruitment strategies for encouraging participation in corporate volunteer programs. Journal of Business Ethics, 49(4), 371-386.

Richey, M. \& Gupta, D., \& O'Mahony, T. K., \& Meyers, L. E., \& Zender, F., \& Vermeer, D. L. (2015, June), The Business Case for Engineering Skills-based Volunteerism in K-12 Education Paper presented at 2015 ASEE Annual Conference and Exposition, Seattle, Washington. 10.18260/p.24846

Sergent, M.T. \& Sedlacek, W. E. (1990). Volunteer motivations across student organizations: A test of personenvironment fit theory. Journal of College Student Development, 31(3), 255-261.

Smith, D.H. Altruism, volunteers, and volunteerism. Journal of Voluntary Action Research (1981).

Stukas, A.A., Snyder, M. \& Gil Clary, E.G. The effects of "mandatory volunteerism" on intentions to volunteer. Psychological Science 10.1 (1999): 59-64.

Wymer Jr., W.W. (2003). Differentiating literacy volunteers: A segmentation analysis for target marketing. International Journal of Nonprofit and Voluntary Sector Marketing, 8(3), 267-285.

Yowell, J.L., Zarske, M.S., Knight, D. \& Sullivan, J.F., (2013) Impact of TEAMS Clubs: An Afterschool Engineering Enrichment Program that Impacts K-12 Students and College Student Leaders. ASEE Paper 2013-6369, Proceedings of the 2013 ASEE Annual Conference \& Exposition, Atlanta, GA. 


\section{Appendices}

\section{Adapted Volunteer Functions Inventory (VFI)}

All items $1-47$ are scored on a 7 point Likert scale basis from $1=$ Strongly disagree to $7=$ Strongly agree. Leading numbers indicate question number in the adapted version.

VFI Motivations for Volunteering (organized here by Function)

Career

1. (VFI-1) Volunteering could have helped me get my foot in the door at a place where I'd like to work.

5. (VFI-10) I saw a potential to make make new contacts that might help my business career.

18. (VFI-15) Volunteering allowed me to explore different career options.

26. (VFI-21) Volunteering had the potential to help me succeed in my chosen profession.

29. (VFI-28) Volunteering experience would look good on my resume.

Social

2. (VFI-2) My friends volunteered.

3. (VFI-4) People I'm close to wanted me to volunteer.

4. (VFI-6) People I know shared an interest in community service.

19. (VFI-17) Others with whom I am close placed a high value on community service.

27. (VFI-23) Volunteering was an important activity to the people I knew best.

Values

6. (VFI-3) I was concerned about those less fortunate than myself.

9. (VFI-8) I was genuinely concerned about the particular group I was serving.

13. (VFI-16) I felt compassion toward people in need.

14. (VFI-19) I felt it was important to help others.

21. (VFI-22) I was able to do something for a cause that was important to me.

\section{Understanding}

16. (VFI-12) Volunteering allowed me to learn more about the cause for which I worked.

17. (VFI-14) Volunteering allowed me to gain a new perspective on things.

20. (VFI-18) Volunteering let me learn through direct "hands on" experience.

28. (VFI-25) I could learn how to deal with a variety of people.

30. (VFI-30) I would be able to explore my own strengths.

\section{Enhancement}

7. (VFI-5) Volunteering made me feel important.

12. (VFI-13) Volunteering increased my self-esteem.

23. (VFI-26) Volunteering made me feel needed.

24. (VFI-27) Volunteering made me feel better about myself.

25. (VFI-29) Volunteering was a way to make new friends. 


\section{Protective}

8. (VFI-7) No matter how bad I'd been feeling, volunteering helped me to forget about it.

10. (VFI-9) By volunteering, I felt less lonely.

11. (VFI-11) Doing volunteer work relieved me of some of the guilt over being more fortunate than others.

15. (VFI-20) Volunteering helped me work through my own personal problems.

22. (VFI-24) Volunteering was a good escape from my own troubles.

VFI Volunteering Outcomes (organized here by Function)

Career

31. (VFI-31) In volunteering with DREAM, I made new contacts that might help my career.

37. (VFI-37) As a volunteer in DREAM, I was able to explore possible career options.

Social

32. (VFI-32) People I knew best knew that I was volunteering for DREAM.

38. (VFI-38) My friends found out that I was volunteering for DREAM.

Values

33. (VFI-33) People I am genuinely concerned about were being helped through my volunteer work for DREAM.

39. (VFI-39) Through volunteering for DREAM, I did something for a cause that I believe in.

\section{Enhancement}

34. (VFI-34) From volunteering in DREAM, I felt better about myself.

40. (VFI-40) My self-esteem was enhanced by performing volunteer work for DREAM.

\section{Protective}

35. (VFI-35) Volunteering in DREAM allowed me the opportunity to escape some of my own troubles.

41. (VFI-41) By volunteering for DREAM, I was able to work through some of my own personal problems.

\section{Understanding}

36. (VFI-36) I learned how to deal with a greater variety of people through volunteering through DREAM. 42. (VFI-42) I was able to learn more about the cause for which I worked by volunteering with DREAM.

\section{VFI Volunteering Satisfaction}

43. (VFI-43) I enjoyed my volunteer experience with DREAM.

44. (VFI-44) My volunteer experience with DREAM was personally fulfilling.

45. (VFI-45) The experience of volunteering with DREAM was a worthwhile one.

46. (VFI-46) I was able to make an important contribution by volunteering in DREAM.

47. (VFI-47) I accomplished a great deal of "good" through my volunteer work with DREAM.

VFI Volunteering Long-Term Intentions (not used)

48. (VFI-48) One year from now, will you be (please circle your best guess as of today): 


\section{Mentors Self-Assessment Survey (MSAS)}

Unless indicated otherwise in parentheses, all items require a Likert scale response on a 5 point basis of: $1=$ Strongly disagree, $2=$ Disagree, $3=$ Neutral, $4=$ Agree, $5=$ Strongly agree.

\section{Outcomes from Participation in DREAM}

1. Participating in DREAM helped strengthen my oral communication skills.

1a. Please explain your answer. (free response)

2. Participating in DREAM helped strengthen my written communication skills.

2a. Please explain your answer. (free response)

3. Participating in DREAM helped strengthen my fundamental engineering skills (i.e. calculs, physics, etc.).

3a. Please explain your answer. (free response)

4. My experience with DREAM impacted my future career plans (after graduation).

4a. Please explain your answer. (free response)

5. Participating in DREAM impacted my satisfaction with my engineering studies.

5a. Please explain your answer. (free response)

6. My involvement in DREAM impacted my undergraduate course selections or major. (Yes/No)

6a. Please explain your answer. (free response)

7. I participated in DREAM because I needed to fulfill a service requirement for a scholarship, program or society. (Yes/No)

7a. If yes, please list the scholarship, program, or society and the number of hours required. If no, please list reasons you desired to participate in DREAM. (free response)

8. What is the greatest benefit that you feel you got out of participating in DREAM? (free response)

\section{Background and Perceptions on Educational Equality and Outreach}

9. Education was valued in my home community.

10. Education was valued in my family.

11. I believe that education is important to society.

12. Before DREAM, I was knowledgeable of underserved communities.

13. Before DREAM, I was involved in service to underserved communities.

14. Before DREAM, I was knowledgeable about underrepresentation in engineering.

15. My volunteering experience with DREAM encouraged me to continue volunteering.

16. My volunteering experience with DREAM affected/will affect my current/future volunteering organization choice.

16a. Please explain your answer. (free response)

17. What is your view on the education disparity facing underserved and underrepresented communities? (free response) 